\title{
2 変数異方性離散分布による渴水期水文量の確率モデル化 \\ Anisotropic Bivariate Discrete Stochastic Model \\ for Hydrological Series in Dry Season
}

長尾正志* , 小西宏和 ${ }^{* *}$, 鈴木正人***

By Masashi Nagao, Hirokazu Konishi and Masato Suzuki

\begin{abstract}
This study presents an extension of the discrete stochastic model used to justify anisotropic bivariate hydrological quantities such as precipitation or runoff discharge in dry season. The theory of discrete distribution is obtained in the form of bivariate binomial distribution and bivariate negative binomial distribution. In those two type of distribution, bivariates have different parameters and correlation. The estimation of parameters is discussed by separating marginal and joint distribution in a maximum likelihood method. The results applied by negative binomial model prove to fit well for the data of runoff discharge series.

Keywords:bivariate distribution, discrete distribution, parameter estimation
\end{abstract}

1. 研究の目的

水資源施設の機能評価や操作法の研究をする場合、入力である河川流量や降水量の確率分布を理論モデル で表現する必要がよくある。しかも、計算上の要求からそれには離散分布が使われることが多い。著者らは 利水用眝水池の取水機能の評価や合理的放流に関連して、2 変数分布としての流入量時系列へ等方性の離散 分布の適用を提案してきた”が、最近異方性をもつ離散分布が利用可能であることが分かってきたので、そ れら理論モデルとその母数推定について報告し、2つの隣接流域からの流出流量時系列の間に相互相関を考 虑した 2 変数モデルを適用した結果を示す。

さて、渴水期の流況の確率分布としての特性としては、1) 各種の正の歪に対応する柔軟性がある２） 顕著な持続性を有する 3 ) 一般に量の小さい領域の確率表現が重視されることが上げられよう。したが って、特に 3 ) との関連において、実用的な上限を設定することが有効である場合もある。以下 2 変数の離 散型確率分布を取り扱う。

2. 異方性 2 変数離散分布モデル

著者らは、上限が有限で共通し、流況に応じて分布形状が変化させうる離散型モデルとして異方性の二項 分布モデル2)や上限はなく共通母数は有するが、形状の変化に対応可能な異方性の負の二項分布モデル 提案を行なってきた。この場合、二項分布では平均＞分散の関係が、負の二項分布では、平均く分散の関係 が要求される。

以下では、理論の導出の詳細については文献を参照して頂くことにして、異方性モデルについてこれら 2 変数離散分布の概要を記述する。

\begin{tabular}{|c|c|c|c|}
\hline$*$ & 正会員 & 工博 & $\begin{array}{l}\text { 名古屋工業大学教授 工学部社会開発工学科 } \\
\text { ( } 466 \text { 名古屋市昭和区御器所町) }\end{array}$ \\
\hline$* *$ & 学生員 & & 名古屋工業大学大学院 工学研究科社会開発工学専攻 \\
\hline * & 正会 & 工博 & 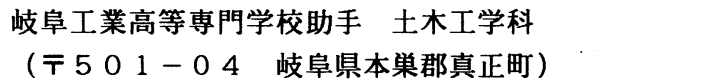 \\
\hline
\end{tabular}


2.1 二項分布モデル

この分布では、隣接した 2 流域間の流出を問題にするときのように、各流域での共通の雨量上限や比流量 上限の存在を想定する場合に有用なものである。

1) 条件付き分布

まず共通の上限 $\mathrm{r}$. 形状母数の異なる 2 变数二項分布に従う変数 $\mathrm{X}_{1} 、 \mathrm{X}_{2}$ の確率母関数は次式で与えら れる4!。

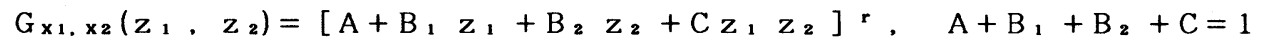

上式を基礎として、形状母数 $\mathrm{a}_{1}, \mathrm{a}_{2}$ を持つ変数 $\mathrm{X}_{1}, \mathrm{X}_{2}$ の条件付き分布は

$p_{i j}=P_{r}\left[X_{1}=j \mid X_{2}=i\right]$

$$
=a_{1}^{j}\left(1-a_{1}\right)^{r-j} \cdot I_{1}^{r-i-j} \cdot I_{s^{i}} \cdot I_{4}^{j} \sum_{s=0}^{m i n(i, j)} C_{s} \cdot r_{r-i} C_{j-s}\left[\frac{I_{1} I_{2}}{I_{3} I_{4}}\right]^{s}
$$

ただし

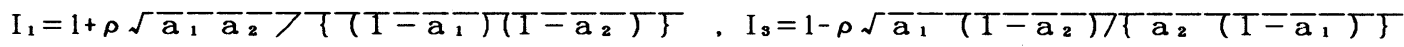

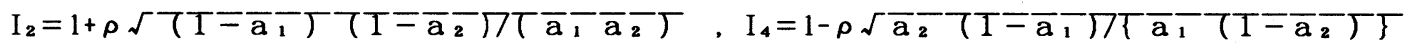

このように、条件付き分布が上限 $\mathrm{r}$ ，形状母数 $\mathrm{a}_{1} ， \mathrm{a}_{2}$ ，および相関母数 $\rho$ を用いて直接的に表記でき たので、確率値の計算や各種シミュレーションなとに有効であると考えている。

2 ）周辺分布と基本統計量

また周辺分布および平均、分散、歪係数は以下のようになる。（ $i=1 、 2)$

$P_{x_{i}}\left(X_{i}\right)={ }_{r} C_{x_{i}}\left(1-a_{i}\right)^{r-x_{i}}\left(a_{i}\right)^{x_{i}}, E\left(X_{i}\right)=r a_{i}$

$V\left(X_{i}\right)=r a_{i}\left(1-a_{i}\right), C_{s}=\left(1-2 a_{i}\right) /\left[\mathrm{ra}_{i}\left(1-a_{i}\right)\right]^{1 / 2}$

さらに、 $\mathrm{X}_{1}$ と $\mathrm{X}_{2}$ との間の相互相関係数 $\rho$ は、C を非負の値として

$$
\rho=\left(\mathrm{C}-\mathrm{a}_{1} \mathrm{a}_{2}\right) / \sqrt{\mathrm{a}_{1}}-\overline{\mathrm{a}}_{2} T\left(\mathrm{~T}=\overline{\mathrm{a}}_{1}\right)\left(\mathrm{T}=\overline{\mathrm{a}}_{2}\right)
$$

なお、。には以下のように上限、下限の存在範囲があることが導ける。

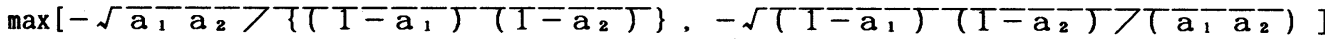

$$
\begin{aligned}
& <\rho<
\end{aligned}
$$

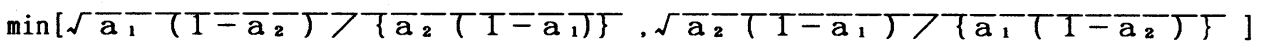

すなわち、範囲の上限（正値）は $\mathrm{a}_{1}=\mathrm{a}_{2}$ に関して対称であり、両者の差が大きいほど小さくなる。なお $\mathrm{a}_{1}=\mathrm{a}_{2}$ では上限は最大値 1 である。つきに、下限（負値）は、 $\mathrm{a}_{1} \mathrm{a}_{2}$ と $\left(1-\mathrm{a}_{1}\right)\left(1-\mathrm{a}_{2}\right)$ の 差が大きいほと、つまり $a_{1}, a_{2}$ 面において $a_{1}+a_{2}=1$ の直線から離れるほと、大きくなり、 $a_{1}+$ $\mathrm{a}_{2}=1$ では最小值 -1 となる。

3 ）条件付き変量の平均、分散

式 (2) の条件付き分布より、 $\mathrm{X}_{2}=\mathrm{s}$ を指定した場合の条件付き変量 $\mathrm{X}_{1}$ の平均および分散が得られる。 結果のみを記述しておく。まず、条件付き平均 $\mu_{1} \cdot\left(X_{1} \mid X_{2}=s\right)$ は指定変量 $X_{2}=s$ に関して線形で ある。また、条件付き分散 $\mu_{2}\left(X_{1} \mid X_{2}=s\right)$ も指定変数に関して線形的な関係にあることが示される。

なお、以上の関係を用いると、条件付き平均値は、次式の通常の回㷌直楾の式に書き直せることが誘導さ れる。なお、この関係は後述の負の二項分布についても成立する。したがって回㷌推定には利用しやすい分 布族であるといえる。

$$
\mu_{1} \cdot\left(\mathrm{X}_{1} \mid \mathrm{X}_{2}\right)=\overline{\mathrm{X}}_{1}+\rho\left(\sigma_{1} / \sigma_{2}\right)\left(\mathrm{X}_{2}-\overline{\mathrm{X}}_{2}\right) \quad\left(\mathrm{X}_{1} \sigma \sigma \text { : 平均、標準偏差 }\right)
$$

4) 積率解としての母数推定

(4) 式より、まず形状母数 $a_{1} 、 a_{2}$ を、 $a_{i}=1-V\left(X_{i}\right) / E\left(X_{i}\right) \quad(i=1,2)$ 
として推定した後、上限 $\mathrm{r}$ 、次式で求めるが、

$$
r=0.5 \times\left[\left\{E\left(X_{1}\right)\right\} / a_{1}+\left\{E\left(X_{2}\right)\right\} / a_{2}\right]
$$

上限 $\mathrm{r}$ は整数であるから、求めた值に最も近い整数として求め直したものを共通上限 $\hat{\mathrm{r}}$ とする。そこで、再 度形状母数を次式で計算する。

$$
\hat{a}_{i}=E\left(X_{i}\right) / \hat{r} \quad(i=1,2)
$$

つぎに定数 $\mathrm{A} 、 \mathrm{~B}_{\mathrm{i}}(\mathrm{i}=1,2)$ ，Cが次のようにして求められる。

まず (5) 式より、相関母数 $\rho$ に標本相関係数を使うと、次式で $\mathrm{C}$ が分かる。

$\hat{\mathrm{C}}=\hat{\mathrm{a}}_{1} \hat{\mathrm{a}}_{2}+\hat{\rho}\left\{\hat{\mathrm{a}}_{1} \hat{\mathrm{a}}_{2}\left(1-\hat{\mathrm{a}}_{1}\right)\left(1-\hat{\mathrm{a}}_{2}\right)\right\}^{1 / 2}$

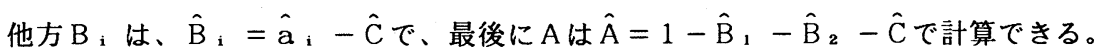

2.2 負の二項分布

先述の結果で、

$$
r=-k(k>0), \quad-\left(B_{i}+C\right)=a_{i}(>0) \quad(i=1,2) .
$$

とおけば、負の二項分布が得られる。これについて簡単に触れておく。なお、この分布では上限は無限大で ある。

1) 周辺分布と基本統計量

まずその周辺分布を通常の表現に改めると、次式のようになる。

$P_{x_{i}}\left(x_{i}\right)=_{x_{i}+k-1} C_{x_{i}} \cdot\left(p_{i}\right)^{k}\left(q_{i}\right)^{x_{i}}\left(x_{i}=0,1,2, \cdots\right)$

ただし、 $\mathrm{p}_{i} \equiv\left(1+\mathrm{a}_{i}\right)^{-1}, \quad \mathrm{q}_{i} \equiv \mathrm{a}_{\mathrm{i}}\left(1+\mathrm{a}_{\mathrm{i}}\right)^{-1}$

また、各種統計量は以下のようである。

平均 $\mathrm{E}\left(\mathrm{X}_{\mathrm{i}}\right)=\mathrm{k} \mathrm{a}_{\mathrm{i}}$, 分散 $\mathrm{V}\left(\mathrm{X}_{\mathrm{i}}\right)=\mathrm{k}_{\mathrm{i}}\left(1+\mathrm{a}_{\mathrm{i}}\right)$

歪係数 $C_{s}=\left(1+2 a_{i}\right) /\left[k a_{i}\left(1+a_{i}\right)\right]^{1 / 2}$

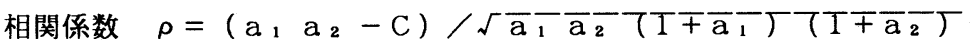

2) 条件付き分布

さらに、条件付き分布は、

$$
\begin{aligned}
& \mathrm{p}_{\mathrm{i} j}=\mathrm{a}_{1^{j}}\left(1+\mathrm{a}_{1}\right)^{-\mathrm{k}-j} \mathrm{I}_{1^{-k-i-j}} \mathrm{I}_{3^{\mathrm{i}}} \mathrm{I}_{4}{ }^{j} \\
& \times \sum_{s=0}^{\min (i, j)}(-1) s \frac{\Gamma(k+i+j-s)}{\Gamma(k+i)} \frac{i !}{s !(i-s) !(j-s) !}\left[\frac{I_{1} I_{2}}{I_{3} I_{4}}\right]^{s}
\end{aligned}
$$

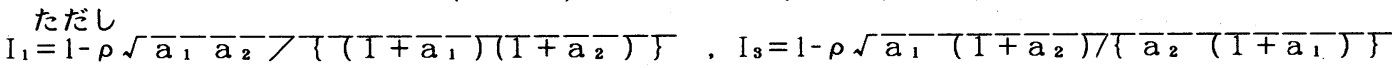

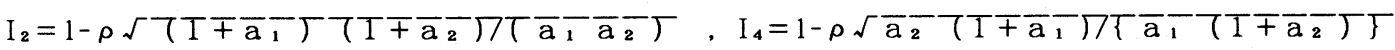

なお、この相関係数には以下のように上限のみの制限が存在する。

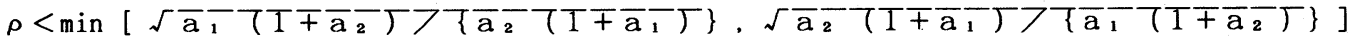

この上限は、 $\mathrm{a}_{1}=\mathrm{a}_{2}$ に関して対称で、 $\mathrm{a}_{1} ， \mathrm{a}_{2}$ の差が大きいほど上限の值は小さくなり、 $\mathrm{a}_{1}=\mathrm{a}_{2}$ において最大 1 となる。なお、上式の [ ] の中の項を $\mathrm{L}_{1}$ および $\mathrm{L}_{2}$ とすると、 $\mathrm{a}_{1}>\mathrm{a}_{2}$ のとき $\mathrm{L}_{1}>$ $\mathrm{L}_{2}$ したがって上限は $\mathrm{L}_{2}$ 、逆の場合は上限は $\mathrm{L}_{1}$ となる。

3) 積率解としての母数推定

平均と分散より、まず形状母数 $\mathrm{a}_{\mathrm{i}}$ を、 $\hat{\mathrm{a}}_{\mathrm{i}}=\mathrm{V}\left(\mathrm{X}_{\mathrm{i}}\right) / \mathrm{E}\left(\mathrm{X}_{\mathrm{i}}\right)$ ) - 1 として推定した後、 $\mathrm{k}$ を次式 の平均値で求める。 $\hat{\mathrm{k}}=0.5 \times\left(\mathrm{E}\left(\mathrm{X}_{1}\right) / \hat{\mathrm{a}}_{1}+\mathrm{E}\left(\mathrm{X}_{2}\right) / \hat{\mathrm{a}}_{2}\right)$ 、さらに形状母数を次式 $a_{i}=E\left(X_{i}\right) / \hat{k}$ で計算し直す。これを標本相関係数を $\rho$ とした(15)式に用いると、Cが判明する。 $\hat{\mathrm{C}}=\hat{\mathrm{a}}_{1} \hat{\mathrm{a}}_{2}-\rho\left\{\hat{\mathrm{a}}_{1} \hat{\mathrm{a}}_{2}\left(1+\hat{\mathrm{a}}_{1}\right)\left(1+\hat{\mathrm{a}}_{2}\right)\right\}^{1 / 2}$ 
最後に、 $\mathrm{B}_{i}$ およびAは、次式から推定できる。

$$
\hat{\mathrm{B}}_{i}=-\hat{\mathrm{a}}_{i}-\hat{\mathrm{C}}(\mathrm{i}=1,2), \quad \hat{\mathrm{A}}=1-\hat{\mathrm{B}}_{1}-\hat{\mathrm{B}}_{2}-\hat{\mathrm{C}}
$$

さらに、この負の二項分布で $\mathrm{k}=1$ とおけば、異方性の 2 変数幾何分布が得られる。

最後に、これら異方性分布において、各母数に等方性（たとえば $\mathrm{a}_{1}=\mathrm{a}_{2}$ ）を仮定すれば、従来得られ ていた結果と完全に合致することが確認できた。

\section{3. 最尤解による母数推定}

積率解による母数推定については先述したが、一般に積桼解より最尤解のほうが統計的に好ましい結果が 得られることが知られている。そこで、最尤解による母数推定の手順を記述する。ところで、既述のように 条件付き分布が分かっているので、それに周辺分布を㨁けた同時分布から対数尤度を求め、これが最大とな ように、各種母数を推定すれば結果が得られるはずである。しかし、相関母数に制限が存在することからこ れを綝り返し演算で求めることは困難であった。そこで以下のように、まず周辺分布の母数を求めた後、相 関母数を推定するという 2 段階の手順で計算することにした。これを負の二項分布の場合について記述して おく。

\section{1 周辺分布の母数推定}

この場合の未知母数は $\mathrm{k} ， \mathrm{a}_{1} ， \mathrm{a}_{2}$ の 3 個であるが、まず $\mathrm{k}$ が異なる母数 $\mathrm{k}_{1} 、 \mathrm{k}_{2}$ を持つとみなし、 これを求めるように考える。それには（12）式の周辺分布から $\mathrm{n}$ 個の標本組 $\left(\mathrm{X}_{\mathrm{i} j \mathrm{j}} ; \mathrm{i}=1 ， 2 ， \cdots, \mathrm{n}:\right.$ $j=1 ， 2 ） に$ 対する対数尤度LLを求め、 $\partial \mathrm{LL} / \partial \mathrm{k}_{\mathrm{j}}=0 ， \partial \mathrm{LL} / \partial \mathrm{a}_{\mathrm{j}}=0$ を各 $\mathrm{j}$ ごとに連立させた、 いわゆる尤度方程式を資料総数 nで割った形式の次式から $\mathrm{k}_{\mathrm{j}}$ を求める ${ }^{5)}$ 。

$$
\frac{1}{n} \sum_{i=1}^{n} \sum_{s=0}^{x_{i j-1}} \frac{1}{k_{j}+s}-\ell n\left[1+\frac{X_{j}}{k_{j}}\right] \equiv D\left(k_{j}\right)=0 \quad(j=1,2)
$$

この式は資料 1 個当たりの対数尤度の $\mathrm{k}$ の增加に伴う変化率と解釈できるものである。実用的には、 $\mathrm{k}_{\mathrm{j}}$ を 順次変えていき上式の関数 $\mathrm{D}\left(\mathrm{k}_{\mathrm{j}}\right)$ ) の值がある微小な許容範囲 $\varepsilon$ a内にあれば、それが解であると判別で きょう。つきに、これら $\mathrm{k}_{1} 、 \mathrm{k}_{2}$ の平均で共通の母数 $\mathrm{k}$ とする。さらに(13)式の関係から標本平均を用い て $a_{i}$ を求める。

\section{2 相関母数の推定}

(12) 式の周辺分布と (16) 式の条件分布の積で同時分布 $f(i, j)=P_{i} \times p_{i j}$ が得られる。この同時分 布は唯一の未知母数 $\rho$ を含む。この（i，j）は同時に取った標本の粗であるから、この意味を分かりやす くするために、これを $n$ 個の標本の $i$ 番目の組 $\left(x_{i}, y_{i}\right)$ に対する値 $f\left(x_{i}, y_{i}\right)$ のように表記す る。したがって対数尤度関数 $L \mathrm{~L}=\Sigma \log \mathrm{f}\left(\mathrm{x}_{\mathrm{i}}, \mathrm{y}_{\mathrm{i}}\right)(\mathrm{i}=1,2, \cdots, \mathrm{n})$ をデータに対して 求め、この值を最大する母数 $\rho$ が最尤推定值を与える。

\section{4. モデルの適用}

4. 1 渇水期の設定

渴水の状態は、本来自然現象である供給と、社会現象である需要との相対関係で決まるものであるから、 単純ではない。しかし自然の流況との関連でいえば、平均、変動係数、歪係数、自己相関性なとの考虑が主 体となるであろう。

\section{2 離散化}

連続量を離散化するのであるから、期間とその間の平均量が現象記述に適切でなければならない。眝水池 による流水管理の場合では、この期間には眝水池の操作単位期間が対応する。現実には適当な単位量を用い 
て放流量、眝水池容量を表現しなければならないので、計算の簡便さと現象表現の正確さを勘案しながら選 定していくことになろう。

\section{3 モデル選定の基準}

さて、以上のような前段階を経て、分布母数を推定しモデル選定を行なっていくが、その際に渴水期の流 量分布のモデ作成に、渴水期の全ての資料をそのまま利用するのが、妥当であろうかという問題がある。 特に議論の出るのは、渴水期とはいっても、ごく稀にかなり大きな值が介入し、それが渴水期を代表してい ると考えられる分布特性を非常に暧昧で、不安定なものにしないかという懸念である。したがって、本研究 では、この欠点を除くために、資料中の最大值から小さいほうに第 2 位、第 3 位と順に資料を除外していき ながら、残された部分標本での母数推定を実施し、適合を計っていくことにした。また、周辺分布の適合性 の判定には、(18)式のD（ $k_{j} ）$ の他に、 $X^{2}$ 一検定を併用した。

4. 4 実資料の当てはめ

宮崎県大淀川綾北夕ム（流域面積148.3 $\left.\mathrm{km}^{2}\right) 、$ 綾南夕゙ム $\left(101.0 \mathrm{~km}^{2}\right)$ の $1966-1986$ 年の日流量を基礎に、平均などの特性から 渴水期を 11 月 2 日からの 120 日間、 2 0 年分とした。また単位期間を 5 日とし、 これを比流量 $\left(\mathrm{m}^{3} / \mathrm{s} / 100 \mathrm{k} \mathrm{m}^{2}\right)$ の形で離散化し、対応する量をそれぞれ、 $\mathrm{X}_{1} 、 \mathrm{X}_{2}$ ととる。なお常時確保される流 量分は除外している。したがって、相互相 関係数を勘案した両者の流量時系列に以上 の異方性離散分布を当てはめてみた。

表一 1 は、その手順と結果の概要を示し たものである。

まず周辺分布の母数推定では、全標本よ り上位標本を除外していくと、平均、標準

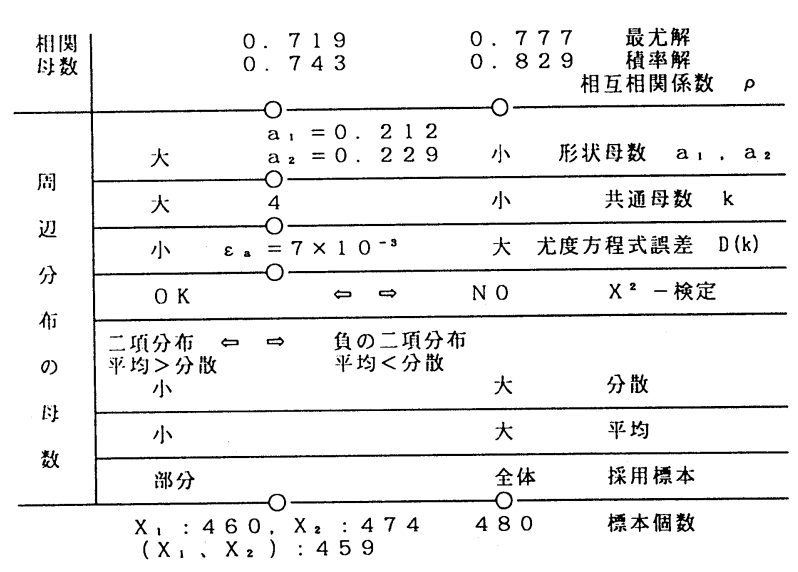

表 -1 母数推定の概念図 偏差はともに減少するが、特に標準偏差の 減少は著しい。したがって、全標本付近で 平均く分散から負の二項分布が適合するが、除外標本が増すにつれて平均＞分散に移り、二項分布が適合す ることになる。この適合性を尤度方程式の誤差およびX ${ }^{2}$ - 検定としてみたのがその上の 2 行である。すな わち、除外標本が少ないうちは、 $\mathrm{X}^{2}$ 一検定 $(1 \%, 5 \%)$ は不合格であったものが、次第に合格に変わっ ていく。また尤度方程式䛊差D (k) は次第に小さくなる。䛊差の許容限界を 対応する係数 $\mathrm{k}_{1} ， \mathrm{k}_{2}$ が定まる。後に平均した近似値を採用することを考えて、これらを整数のうちから 選ぶことにする。ここでは $\mathrm{k}_{1}=2, \mathrm{k}_{2}=5$ から共通母数には $\mathrm{k}=4$ を採用する。

つきに形状母数 $\mathrm{a}_{1} ， \mathrm{a}_{2}$ はそれぞれの平均を $\mathrm{k}$ 割って、 $\mathrm{a}_{1}=0.212 ， \mathrm{a}_{2}=0.229$ となる。なお、この 場合、標本数は全体では480、部分標本では $X_{1} 、 X_{2}$ のそれぞれで $460 、 474$ となる。最後に相関母数を 求めるために以上の採用域の共通部分の 459 個について最尤解、および積率解（標本相関係数）で求めた結 果は、 $\rho=0.719$ および0.743である。なお、全標本での結果は、それぞれ0.777および0.829 となり、最 尤解が積率解より若干小さな値となっているが、それほと大きな差異ではない。

つぎに適合結果を経験分布と理論分布の比較として示そう。図ー 1 は周辺分布の比較で、経験分布では若 干全体から突出した部分が見受けられるが、全体的には満足できる適合結果といえよう。なお $x^{2}$ 検定では $\mathrm{X}_{1}$ ではほぼ $1 \%$ 程度、 $\mathrm{X}_{2}$ では $5 \%$ の有位水準で適合性が認められる。ついで図ー 2 は同時分布の比較で 
ある。ここでも周辺分布における場合と同様に、部分的にバラッキが見られるが、総合してほぼ妥当な適合 結果であるといえよう。
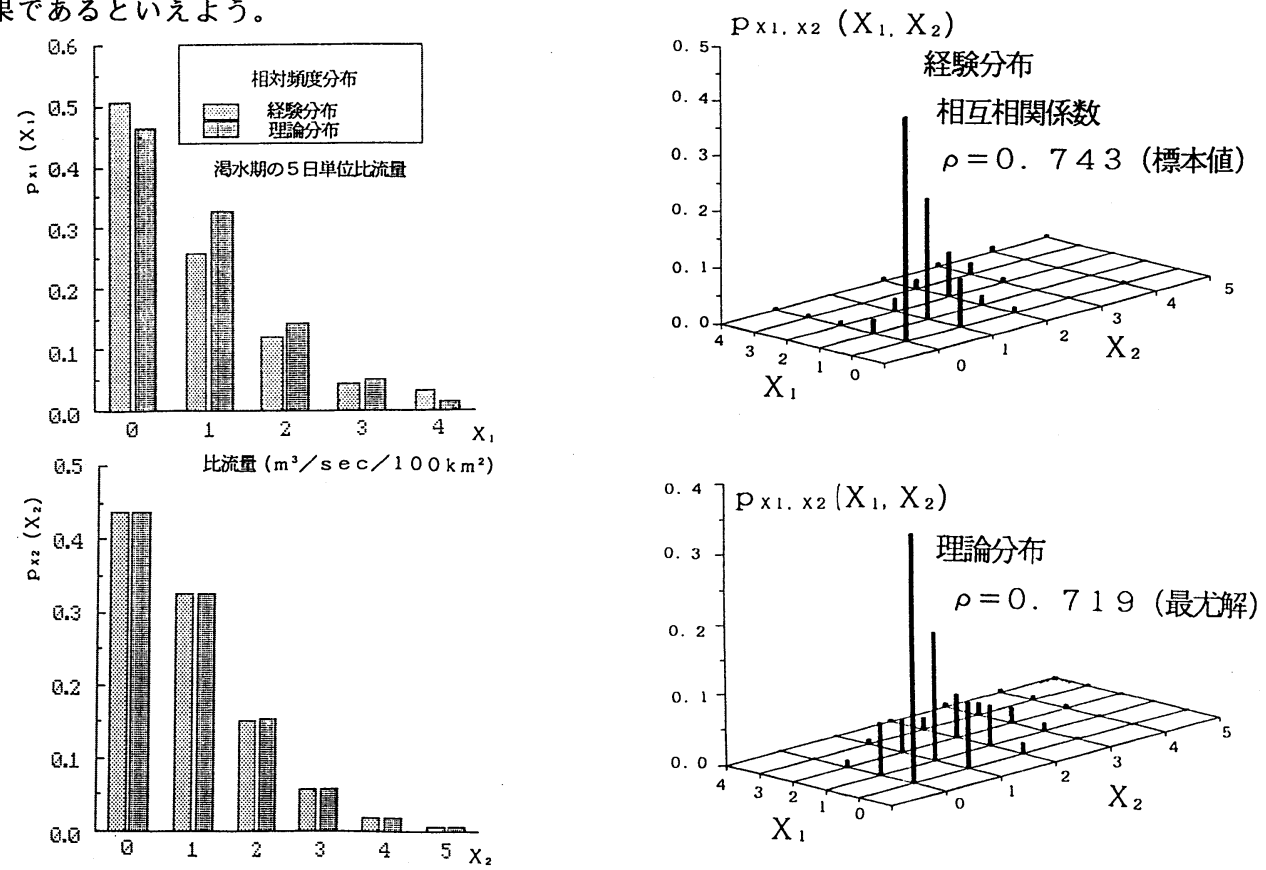

図-1 経験分布と理論分布の比較（周辺分布）図-2 経験分布と理論分布の比較（同時分布）

従来相関を勘案した離散分布として、等方性の理論しか得られていなかったが、上記のように異方性が勘 案できたので、採用される理論分布系の選択に柔軟性がでることになった。もちろん、以上の異方性分布で $X_{1} 、 X_{2}$ の母数を共通に取れば、等方性分布が得られる。利用分野としては、この例のように雨量や比流 量などを対象とした相互相関としての利用や、時系列間の分布特性の違いを表現するには非等方性分布を、 特性が共通として時系列的に扱う場合などには等方性分布を適用することが考えられる。

しかし、各種母数の一括した推定法や、合理的な判定基準の策定、2 変数以上の多変数への拡張なと残さ れた課題も少なくないので、これらは今後の目標としていくつもりである。

\section{参考文献}

1) 長尾正志、池田吉隆：流量相関を考慮した利水用眝水池の機能評価に関する確率過程論の応用、第23回 水理講演会論文集、1978.2、pp. 247-255

2 ) 長尾正志、小西宏和: 形状母数の異なる 2 変数二項分布の理論モデル、平成 3 年度土木学会中部支部研 究発表会講演概要集、1992.3、pp. 159-160

3 ）長尾正志、小西宏和、鈴木正人：異方性 2 変数離散分布の理論一負の二項分布を中心として一、第47回 土木学会学術講演会概要集、1992.9、第 II 部門、pp. 668-669

4 ) C. B. Edwards and J.Gurlands : A Class of Distributions applicable to Accidents, Jour. Amer. Statist. Ass., 56, pp. 503-517, 1961

5 ) Norman L. Johnson and Samue1 Kotz: Discrete Distributions, Houghton Mifflin Co., 1969, pp. $131-132$ 